\title{
Duct-to-Duct Biliary Anastomosis Yields Similar Outcomes to Roux-en-Y Hepaticojejunostomy in Liver Transplantation for Primary Sclerosing Cholangitis
}

\author{
Bandar Al-Judaibi ${ }^{1,2,}$; Roberto Hernandez Alejandro ${ }^{1}$; Julia Uhanova ${ }^{1}$; Paul Marotta ${ }^{1}$; \\ Mahmoud Mosli ${ }^{3}$; Natasha Chandok ${ }^{1}$ \\ ${ }_{2}^{1}$ Multi Organ Transplant Unit, Departments of Medicine and General Surgery, University of Western Ontario, London, Canada \\ 2 Department of Medicine, King Saud University, Riyadh, Saudi Arabia \\ ${ }^{3}$ Department of Medicine, King Abdulaziz University, Jeddah, Saudi Arabia \\ ${ }^{*}$ Corresponding Author: Bandar Al-Judaibi, Multi Organ Transplant Unit, Departments of Medicine and General Surgery, University of Western Ontario, London, Canada. Tel:+44-5196858500, \\ Fax:+44-5196632907, E-mail: bandaraljudaibi@gmail.com
}

Received: March 7, 2014; Revised: February 17, 2015; Accepted: March 31, 2015

\begin{abstract}
Background: While Roux-en-Y hepaticojejunostomy (RYH) is the common anastomotic technique for liver transplantation (LT) in patients with primary sclerosing cholangitis (PSC), duct-to-duct (DD) reconstruction may be used if the recipient common bile duct is normal. There are conflicting observational data on the rate of success of DD reconstruction versus RYH, in PSC.

Objectives: The aim of this study was to assess the safety and efficacy of DD anastomosis, compared to RYH reconstruction, among adults transplanted for PSC.

Patients and Methods: All adult patients, who underwent primary LT for PSC between 1990 and 2012, were evaluated, according to type of biliary reconstruction. Recipient and graft survival, postoperative medical and surgical complications, and postoperative resource utilization rates were compared between the two groups.

Results: Totally, 73 patients fulfilled the inclusion criteria. Of them, 58 had RYH and 15 had DD reconstruction. A total of 53 subjects (73\%) were male, with the mean age \pm standard deviation at LT of $43.3 \pm 14.4$ years. Rates of recipient mortality, graft failure, biliary complications, acute cellular rejection, and reoperation were similar in both groups. Postoperative cholangiography was used more frequently in patients with DD reconstruction (33.3\% vs. 8.6\%, $\mathrm{P}=0.026$ ).

Conclusions: In selected recipients with PSC, DD reconstruction is a safe and efficacious technique, with long-term clinical outcomes comparable to RYH.
\end{abstract}

Keywords: Primary Sclerosing Cholangitis; Liver Transplantation; Roux-en-Y Anastomosis

\section{Background}

Primary sclerosing cholangitis (PSC) is a chronic liver disease characterized by cholestasis, biliary inflammation and duct stricture that will lead to cirrhosis in approximately half of subjects (1-5). There are no curative medical treatments for PSC, and the only definitive treatment for advanced disease is liver transplantation (LT) (1, 6-8). There are two main techniques for biliary reconstruction of the transplanted liver: duct-to-duct (DD) anastomosis, and Roux-en-Y hepaticojejunostomy (RYH). Historically, the success rates of DD anastomosis have been lower than RYH, because of the risk of anastomotic strictures associated with the former technique $(9,10)$. Given that RYH is associated with several complications, including gastrointestinal bleeding, bacterial overgrowth, cholangitis and biloma formation (11-13), there has therefore existed a trend towards perform- ing DD anastomosis, in suitable PSC patients, to avoid the morbidity of RYH. Furthermore, DD anastomosis has the added advantage of facilitating endoscopic retrograde cholangiography (ERCP) post-LT, if clinically warranted. Given the controversial and conflicting literature surrounding DD anastomosis in PSC, further observational data are necessary to justify this surgical approach.

\section{Objectives}

The primary objective of this study was to assess the safety and efficacy of DD anastomosis, compared to RYH reconstruction, among adults transplanted for PSC. The secondary objective was to analyze the postoperative resource utilization rates between the two groups. 


\section{Patients and Methods}

From the liver transplant database at the multi organ transplant unit of the University of Western Ontario, London, Canada, all subjects $\geq 18$ years old, who underwent primary LT between January 1997 and January 2012 for PSC, were identified and stratified by type of biliary drainage performed at the time of surgery.

All subjects were diagnosed with PSC prior to transplantation and underwent an extensive workup with cross-sectional abdominal imaging and cholangiograms [either ERCP or magnetic resonance cholangiopancreatography (MRCP)]. Subjects who underwent LT had either end-to-end DD anastomosis or RYH reconstruction. The DD anastomosis was performed in select cases, where the recipient extrahepatic duct looked grossly normal or the recipient had previous surgery or extensive bowel edema that precluded the safe creation of a Roux loop. Among patients who underwent DD anastomosis, end-to-end, rather than end-to-side, is the preferred method of anastomosis at our center, as it facilitates therapeutic intervention by ERCP, if required.

\subsection{Data Collection}

Following approval by the Institutional Review Board at University of Western Ontario, London, Canada, baseline clinical and demographic data were collected for each subject, using hospital records. Recipient and graft survival, postoperative medical and surgical complications, and postoperative health resource utilization rates were compared between the two groups.

\subsection{Statistical Analysis}

Categorical variables were reported as frequencies and percentages, and continuous variables were reported as means with standard deviations (SDs) or medians. Differences between groups were examined using the $t$ test, or Wilcoxon two-sample test, where appropriate, for continuous variables and by the $\chi^{2}$ test, or Fisher's exact test, where appropriate, for categorical variables. All statistical tests were two-sided and differences were considered significant when $\mathrm{P}<0.05$. Statistical analyses were performed using SAS Version 9.1.2 (SAS Inc., Cary, NC, USA).

\section{Results}

Totally, 73 adult patients underwent primary LT for PSC. Of them, 58 patients (79.4\%) had RYH and 15 patients (20.5\%) had DD reconstruction. A total of 53 patients were male (73\%) and the mean \pm SD age at LT was $43.3 \pm 14.4$ years. Baseline recipient characteristics are summarized in Table 1 . The mean length of hospital stay in intensive care unit was shorter in the RYH compared to DD group (4.8 days vs. 9.9 days, $\mathrm{P}=0.06$ ). However, the total length of hospital stay was similar between the two groups. There was no statistically significant differences seen in recipient death (17.2\% vs. $13.3 \%$, P > $0.999)$, graft failure (22.4\% vs. $20 \%, P>0.999)$, biliary complications ( $8.6 \%$ vs. $13.3 \%, \mathrm{P}=0.627$ ), need for reoperation (27.6\% vs. $33.3 \%, \mathrm{P}=0.751)$, readmission (50\% vs. $26.7 \%, \mathrm{P}=0.148)$ or retransplantation ( $14 \% \mathrm{vs.} 0 \%, \mathrm{P}=$ 0.191 ), between the RYH and the DD groups. More cholangiograms (through ERCP or MRCP) were needed post LT for DD patients, compared to RYH patients $(33.3 \%$ vs. $8.6 \%, \mathrm{P}=0.026$ ), although there were otherwise no statistically significant differences between the two groups in postoperative complications or resource utilization after LT. Two patients developed anastomotic biliary stricture in the DD group. In the RYH group, two patients were diagnosed with bile leak, one patient had a non-anastomotic biliary stricture, one patient was diagnosed with biliary sump syndrome, and one patient was diagnosed with bile leak by hepatobiliary iminodiacetic acid scan (Table 2). The most common identifiable cause of death post-LT in RYH group was cancer. Causes of death are listed in Table 3. There was no statistically significant difference in rate or causes of graft failure, between the two groups. The two most common causes of graft failure were PSC recurrence and chronic rejection (Table 4). Eight patients required retransplantation; one of whom underwent LT thrice, after loss of the first two grafts for chronic ductopenic rejection and hepatic artery thrombosis.

\begin{tabular}{|c|c|c|c|}
\hline Characteristics & Roux-en-Y $(n=58)$ & $\operatorname{DD}(n=15)$ & P Value \\
\hline Mean age, $\mathrm{y}^{\mathrm{b}}$ & $59.0(47-81)$ & $58.0(30-76)$ & 0.973 \\
\hline Male Gender ${ }^{C}$ & $39(67.2)$ & $14(93.3)$ & 0.054 \\
\hline MELD score ${ }^{b}$ & $18.0(8-39)$ & $17.0(10-29)$ & 0.904 \\
\hline \multicolumn{4}{|l|}{$\begin{array}{l}\text { Inflammatory bowel } \\
\text { disease }^{\mathrm{C}}\end{array}$} \\
\hline Ulcerative colitis & $26(44.8)$ & $11(73.3)$ & $>0.999$ \\
\hline Crohn's disease & $10(17.2)$ & $2(13.3)$ & 0.081 \\
\hline \multicolumn{4}{|l|}{ Comorbidities $^{c}$} \\
\hline Cholangiocarcinoma & $2(3.5)$ & $0(0.0)$ & $>0.999$ \\
\hline Dialysis & $4(7.6)$ & $0(0.0)$ & 0.572 \\
\hline Renal Insufficiency & $1(1.7)$ & $0(0.0)$ & $>0.999$ \\
\hline Hypertension & $2(3.5)$ & $0(0.0)$ & $>0.999$ \\
\hline CAD & $1(1.7)$ & $0(0.0)$ & $>0.999$ \\
\hline Diabetes & $3(5.2)$ & $1(6.7)$ & $>0.999$ \\
\hline
\end{tabular}

a Abbreviation: CAD, Coronary Artery Disease; DD, Duct-to-duct; MELD, Model for End-Stage Liver Disease.

b Data are presented as median (min-max)

c Data are presented as No. (\%). 
Al-Judaibi B et al.

Table 2. Outcomes Post-Liver Transplantation for Primary Sclerosing Cholangitis by Biliary Reconstruction ${ }^{a}$

\begin{tabular}{|c|c|c|c|c|}
\hline Post-LT Outcome & Overall $(n=73)$ & Roux-en-Y $(n=58)$ & Duct-to-Duct $(\mathrm{n}=15)$ & P Value \\
\hline Recipient Death $^{\text {b }}$ & $12(16.4)$ & $10(17.2)$ & $2(13.3)$ & $>0.999$ \\
\hline Graft Failure $^{b}$ & $16(21.9)$ & $13(22.4)$ & $3(20.0)$ & $>0.999$ \\
\hline Biliary leak or stricture ${ }^{b}$ & $7(9.6)$ & $5(8.6)$ & $2(13.3)$ & 0.627 \\
\hline Reoperation ${ }^{b}$ & $21(28.8)$ & $16(27.6)$ & $5(33.3)$ & 0.751 \\
\hline Readmission $^{b}$ & $33(45.2)$ & $29(50.0)$ & $4(26.7)$ & 0.148 \\
\hline Re-transplantation ${ }^{b}$ & $8(11.1)$ & $8(14.0)$ & $0(0.0)$ & 0.191 \\
\hline Need for Cholangiogram ${ }^{b}$ & $10(13.7)$ & $5(8.6)$ & $5(33.3)$ & 0.026 \\
\hline LOS, d, Median & 14.0 & 15.0 & 13.5 & 0.670 \\
\hline ICU LOS, days, Median & 3.0 & 2.5 & 6.0 & 0.070 \\
\hline Follow-up, mon, Median & 133.0 & 145.5 & 122.0 & 0.128 \\
\hline
\end{tabular}

a Abbreviations: Post-LT, Post-Liver Transplantation.

b Data are presented as No.(\%).

Table 3. Causes of Death ${ }^{\mathrm{a}, \mathrm{b}}$

\begin{tabular}{lcc}
\hline & Roux-en-Y $(\mathbf{n}=\mathbf{5 8})$ & DD $(\mathbf{n}=\mathbf{1 5})$ \\
\hline Number of deaths & 10 & 2 \\
Cancer & $3(5.2)$ & $0(0.0)$ \\
Graft failure & $1(1.7)$ & $1(6.7)$ \\
Cardiac death & $1(1.7)$ & 0 \\
Multi-organ failure ${ }^{\mathrm{c}}$ & $2(3.5)$ & 0 \\
Unknown & $3(5.2)$ & $1(6.7)$ \\
\hline
\end{tabular}

a Data are presented as No.(\%).

b Abbreviations: DD, duct-to-duct.

${ }^{\mathrm{C}}$ Includes a duodenal perforation.

Table 4. Causes of Graft Failure ${ }^{a}$

\begin{tabular}{lcc}
\hline & Roux-en-Y & DD \\
\hline Graft failure & $13(22.4)$ & $3(20.0)$ \\
\hline PSC recurrence & $8(13.8)$ & $1(6.7)$ \\
$\begin{array}{l}\text { Chronic ductope- } \\
\text { nic rejection }\end{array}$ & $2(3.5)$ & $1(6.7)$ \\
$\begin{array}{l}\text { Hepatic artery } \\
\text { thrombosis }\end{array}$ & $1(1.7)$ & $0(0.0)$ \\
$\begin{array}{l}\text { Primary non- } \\
\text { function }\end{array}$ & $1(1.7)$ & $0(0.0)$ \\
\hline \begin{tabular}{l} 
Unknown \\
\hline
\end{tabular} & $1(1.7)$ & $1(6.7)$ \\
\hline
\end{tabular}

a Abbreviations: DD, Duct-to duct; PSC, primary sclerosing cholangitis.

Table 5. Vascular Complications ${ }^{\text {a }}$

\begin{tabular}{lccc}
\hline & Roux-en-Y & DD & P Value \\
\hline Portal vein thrombosis & $2(3.5)$ & $1(6.7)$ & 0.504 \\
Hepatic artery thrombosis & $1(1.7)$ & $0(0.0)$ & $>0.999$ \\
Hepatic artery stenosis & $3(5.2)$ & $0(0.0)$ & $>0.999$ \\
\hline
\end{tabular}

a Abbreviation: DD, duct-to-duct.
Table 6. Donor Characteristics

\begin{tabular}{|c|c|c|c|}
\hline Characteristics & Roux-en-Y $(n=58)$ & $\mathrm{DD}(\mathrm{n}=15)$ & P Value \\
\hline Mean age, $y^{a}$ & $39.0(3-69)$ & $58.0(21-76)$ & $<0.001$ \\
\hline $\begin{array}{l}\text { Male Gender, } \\
\text { No. }(\%)\end{array}$ & $35(65.3)$ & $9(60.0)$ & $>0.999$ \\
\hline $\begin{array}{l}\text { Type of donor, } \\
\text { No. (\%) }\end{array}$ & & & $>0.999$ \\
\hline $\begin{array}{l}\text { Donation after } \\
\text { cardiac death }\end{array}$ & $51(87.9)$ & $14(21.5)$ & \\
\hline $\begin{array}{l}\text { Donation after } \\
\text { brain death }\end{array}$ & $2(3.5)$ & $0(0.0)$ & \\
\hline Living donor & $5(8.6)$ & $1(6.7)$ & \\
\hline $\begin{array}{l}\text { Cold ischemic } \\
\text { time, } h^{\text {a }}\end{array}$ & $6.7(1-13)$ & $6.7(2-13)$ & 0.838 \\
\hline $\begin{array}{l}\text { Rewarm } \\
\text { ischemic time, } \\
\text { min }^{\text {a }}\end{array}$ & $53.0(2-45)$ & $45.0(12-70)$ & 0.173 \\
\hline
\end{tabular}

The donor characteristics and incidence of vascular complications post-LT were not significantly different in the DD group, compared to the RYH group (Tables 5 and 6). Only one patient developed intrahepatic disease in the RYH group, secondary to hepatic artery stenosis and prolonged cold ischemic time. None of the patients had cytomegalovirus CMV disease or blood group incompatibility from liver donors.

\section{Discussion}

The RYH has historically been the method of choice for hepatic transplantation for PSC. The theorized basis for this surgical preference is that the distal common bile duct of the recipient may be diseased from chronic PSC, and as such a DD anastomosis may increase the risk of biliary sequels and even cholangiocarcinoma following LT (14). 
In this study, the incidence of biliary leak or biliary stricture were not statistically different in the RYH group, compared to the DD group ( $8.6 \%$ versus $13.3 \%, \mathrm{P}=0.95$ ), therefore challenging the historical convention of RYH as the default anastomotic technique in PSC recipients undergoing LT. This finding is corroborated in other, albeit small, single-center experiences. For instance, in a retrospective study of 53 PSC patients who underwent LT, Esfeh et al. also found that the biliary complication rate was not significantly higher in the DD group, compared to $\mathrm{RYH}$ group ( $11 \%$ vs. $4 \%, \mathrm{P}=0.32)(14)$. Likewise, in a study by Distante et al. the incidences of biliary stricture and biliary leak were not significantly higher in DD patients compared to RYH patients (19\% vs. $10 \%$ and $6 \%$ vs. $20 \%$, P value non-significant) (15). In another publication by Heffron et al. involving 60 PSC patients, who underwent LT, 22 of whom had DD reconstruction, there was also no significant difference in the rates of anastomotic stricture or biliary leak (16). In a UK liver transplant registry study of 264 PSC patients, who underwent LT, including 264 subjects with RYH and 98 with DD anastomosis, the incidence of biliary leak was not significantly higher in the DD group, compared to the RYH group ( $7 \%$ vs. $4 \%, \mathrm{P}=$ $0.26)$, although biliary strictures occurred more often in the DD group ( $8 \%$ vs. $2 \%, P=0.05$ ) (9).

Graft failure and recipient death were not significantly different in the DD group, compared to the RYH group, in the present study. This finding conflicts with the UK liver transplant registry database study of PSC recipients, where the mean graft survival was 85 months in the RYH group, compared to the 74 months of the DD group $(\mathrm{P}=$ 0.034 ) (9). However, the causes of death and a detailed analysis of survival differences between the groups were not clear in the UK study, preventing any meaningful conclusions to be drawn (9). Other publications, such as that by Damrah et al. have determined no survival differences when patients were stratified by biliary anastomotic technique (17).

There are several limitations to our study. First, the present study was a retrospective cohort analysis, with a small sample size, raising the possibility of a type $1 \mathrm{er}-$ ror. That being said, the sample size of our study is larger than other published case series, and our study also has the strength of long-term follow-up across different eras for transplantation. Reliable long-term follow-up data is particularly lacking in registry-based studies. While our study may also be limited in external validity due to data derived from a single-center, our findings appear to coincide with multiple published series $(10,18)$. It should be noted in our study that DD anastomosis was performed in select cases, where the recipient extrahepatic duct looked grossly normal or the recipient had previous surgery or extensive bowel edema that precluded safe creation of a Roux loop and this would be an interesting area for future research.

In conclusion, DD anastomosis represents an efficacious and safe method in selected PSC patients who undergo
LT, compared to RYH, and the overall clinical outcomes appear comparable between the two techniques.

\section{Acknowledgements}

The authors wish to thank Mr. Neil Shankar and Mr. Michael Bloch for their assistance in data collection, as well as the multi-organ transplant team at London Health Science Center.

\section{Funding/Support}

Program for Experimental Medicine Research Award, Western University.

\section{References}

1. Chandok N, Hirschfield GM. Management of primary sclerosing cholangitis: conventions and controversies. Can J Gastroenterol. 2012;26(5):261-8.

2. Potthoff A, Hahn A, Kubicka S, Schneider A, Wedemeyer J, Klempnauer J, et al. Diagnostic value of ultrasound in detection of biliary tract complications after liver transplantation. Hepat Mon. 2013;13(1):e6003.

3. Ozkurt H, Keskiner F, Karatag O, Alkim C, Erturk SM, Basak M Diffusion Weighted MRI for Hepatic Fibrosis: Impact of b-Value. Iran J Radiol. 2014;11(1):e3555.

4. Sahmeddini MA, Amini A, Naderi N. The effect of octreotide on urine output during orthotopic liver transplantation and early postoperative renal function; a randomized, double-blind, placebo-controlled trial. Hepat Mon. 2013;13(9):e12787.

5. Dhiman P,Malhotra S. Overlap syndromes: an emerging diagnostic and therapeutic challenge. Saudi J Gastroenterol. 2014;20(6):342-9.

6. Angulo P, Lindor KD. Primary sclerosing cholangitis. Hepatology. 1999;30(1):325-32.

7. Schmitz V, Neumann UP, Puhl G, Tran ZV, Neuhaus P, Langrehr JM Surgical complications and long-term outcome of different biliary reconstructions in liver transplantation for primary sclerosing cholangitis-choledochoduodenostomy versus choledochojejunostomy. Am J Transplant. 2006;6(2):379-85.

8. Pratico AD, Salafia S, Barone P, La Rosa M, Leonardi S. Type Il Autoimmune Hepatitis and Small Duct Sclerosing Cholangitis in a Seven Years Old Child: An Overlap Syndrome? Hepat Mon. 2013;13(12):e14452.

9. Welsh FK, Wigmore SJ. Roux-en-Y Choledochojejunostomy is the method of choice for biliary reconstruction in liver transplantation for primary sclerosing cholangitis. Transplantation. 2004;77(4):602-4.

10. Solano E, Khakhar A, Bloch M, Quan D, McAlister V, Ghent C, et al Liver transplantation for primary sclerosing cholangitis. Transplant Proc. 2003;35(7):2431-4

11. Bubak ME, Porayko MK, Krom RA, Wiesner RH. Complications of liver biopsy in liver transplant patients: increased sepsis associated with choledochojejunostomy. Hepatology. 1991;14(6):1063-5.

12. Icoz G, Kilic M, Zeytunlu M, Yaprak O, Arikan C, Yuzer Y, et al Roux-en-Y bleeding after living donor liver transplantation: a novel technique for surgical treatment. Transplant Proc. 2003;35(4):1463-5.

13. Said A, Safdar N, Lucey MR, Knechtle SJ, D'Alessandro A, Musat A et al. Infected bilomas in liver transplant recipients, incidence, risk factors and implications for prevention. Am J Transplant. 2004;4(4):574-82.

14. Esfeh JM, Eghtesad B, Hodgkinson P, Diago T, Fujiki M, Hashimoto $\mathrm{K}$, et al. Duct-to-duct biliary reconstruction in patients with primary sclerosing cholangitis undergoing liver transplantation. HPB (Oxford). 2011;13(9):651-5.

15. Distante V, Farouk M, Kurzawinski TR, Ahmed SW, Burroughs AK Davidson BR, et al. Duct-to-duct biliary reconstruction following liver transplantation for primary sclerosing cholangitis. Transpl Int.1996;9(2):126-30. 


\section{Al-Judaibi B et al.}

16. Heffron TG, Smallwood GA, Ramcharan T, Davis L, Connor K, Martinez E, et al. Duct-to-duct biliary anastomosis for patients with sclerosing cholangitis undergoing liver transplantation. Transplant Proc. 2003;35(8):3006-7.

17. Damrah O, Sharma D, Burroughs A, Rolando N, Fernando B, Davidson $\mathrm{B}$, et al. Duct-to-duct biliary reconstruction in orthotopic liver transplantation for primary sclerosing cholangitis: a viable and safe alternative. Transpl Int. 2012;25(1):64-8.

18. Graziadei IW, Wiesner RH, Marotta PJ, Porayko MK, Hay JE, Charlton $\mathrm{MR}$, et al. Long-term results of patients undergoing liver transplantation for primary sclerosing cholangitis. Hepatology. 1999;30(5):1121-7. 